\title{
Del armisticio, como factor estructural e histórico en Colombia, a la paz positiva ${ }^{1}$.
}

\section{From armistice, as a structural and historical factor in Colombia, to positive peace}

\author{
Eduardo Palencia Ramos ${ }^{2}$ \\ María Leonor Ramos Morales ${ }^{3}$ \\ RESUMEN
}

El siguiente artículo trata de hacer una aproximación epistemológica a dos objetivos: primero; trata de demostrar que la paz negativa no ha resuelto problemas endémicos a nivel social y es la causante de, posteriormente, otros conflictos, quizás más cruentos. Y, segundo: la materialización del estado social de derecho coadyuva a que cambie la idea de paz imperante y transcienda a la positiva en la cual se busca solucionar irregularidades sociales.

\section{Palabras Clave:}

Paz positiva, paz negativa, estado social de derecho, conflicto colombiano, amnistía, indulto

\footnotetext{
${ }^{1}$ El presente artículo es un avance teórico de la tesis doctoral intitulada: Los elementos del perdón en las ejecuciones extrajudiciales y su traslación hacia la paz positiva".

2 Docente investigador de la universidad Simón Bolívar - Barranquilla. Magister en ciencia política y derecho público- mención: ciencia política. Doctorante de Métodos Alternos de Solución de Conflictos. Universidad Autónoma Nuevo León México. epalencia@unsimonbolivar.edu.co

${ }^{3}$ candidata al sistema nacional de investigación; Doctora en métodos de solución de conflictos, por la universidad Autónoma de Nuevo León; master en MASC por la universidad autónoma de Nuevo León; Licenciatura en Educación por la universidad pedagógica nacional; catedrática e investigador de la facultad de derecho y criminología de UANL. Ramos.leonor@gmail.com.
}

Recibido: 19 de abril de 2019. Aprobado: 3 de junio de 2019. 


\begin{abstract}
ABSTRAC
The following article tries to make an epistemological approach to two objectives: first; It tries to show that the negative peace has not solved endemic problems at the social level and is the cause of, subsequently, other conflicts, perhaps more cruel. And, second: the materialization of the social state of law helps change the idea of prevailing peace and transcends the positive one in which social irregularities are sought.
\end{abstract}

\title{
Key words:
}

Positive peace, negative peace, social state of law, Colombian conflict, amnesty, pardon

\section{Introducción}

La lucha armada en Colombia ha sido inexorablemente el elemento característico más sobresaliente en la historia de la nación, ha de comprenderse, como una especie de corolario, que las repercusiones de este evento han causado un detrimento en todas las estructuras del estado. De tal forma es inferencial que los miembros del tejido social, desde diversas etapas, han arrostrado las conflagraciones sin tener importantes espacios de tranquilidad y sosiego, por tal motivo considerar a la paz como objetivo, más que un prurito es una necesidad histórica.

Los acontecimientos bélicos experimentados por la nación no solo se circunscriben a la lucha guerrillera sino también a enfrentamientos entre facciones políticas, que imbuidas por intereses de poder intentaban eliminar al adversario mediante actos conminatorios. Dichos episodios violentos eclosionan desde el advenimiento mismo de la república, en ese momento las luchas eran para determinar la forma de estado que debía acoger la nueva nación. Centralistas y federalistas se enfrascaron en un una contienda sin cuartel en la que los resultados fueron funestos desde el punto de vista humano; no obstante, lo que quizás fue la consecuencia más grave, fue el surgimiento de la idea que al oponente se le debe enfrentar con métodos represivos si se quiere evitar su surgimiento. 
La concepción antes enunciada determinó entonces un talante político fundado en lo coercitivo, así se fueron desarrollando las contiendas electorales, puesto que las disputas entre los partidos políticos se convirtieron en espacios de desprecio por el oponente y de cruenta animadversión. Este episodio de la historia nacional, conocido como la violencia, signó gran parte del devenir en el país, porque enfrentó, no solo a militantes de las colectividades, sino que también avasalló a quienes simpatizaban con las ideas de estas, lo cual significa que quien acabó arrostrando las funestas consecuencias de estas hostilidades fueron los miembros de la sociedad civil sin vestigios de poder.

Ante estas vicisitudes marcadas por lo virulento, la respuesta de los dirigentes de partidos fue la utilización de mecanismos que impidieran la suscitación de acontecimientos conflictivos. En tal sentido se optó por las amnistías o indultos, como una forma de lograr "acuerdos" entre los poderosos y recomenzar el camino hacia la consolidación institucional y pacífica.

Este evento, que como ya se mencionó, fue consuetudinario en la política nacional, no solo sirvió para lograr la pacificación de las hostilidades entre los partidos sino que fue la base para resolución de conflictos entre algunas guerrillas y el estado colombiano. Con la eclosión de este medio se dimensionó una modalidad de paz cuyas características resaltaban la ausencia de hostilidades. Este tipo de paz según Galtung (2011) es denominada negativa y se materializa principalmente por la carencia de conflictos.

No es entonces una veleidad que la cosmovisión de la paz en la sociedad colombiana obedezca a este tipo en particular, de allí se entiende que se haya tomado como fundamento para dirimir cualquier situación bélica en la nación, y además para confeccionar una idea muy limitada sobre los propósitos pacíficos, si se asume que no considera a aspectos sustanciales que realmente solucionen un conflicto. 
No obstante con el advenimiento de la constitución política de 1991 y con la refundación epistemológica, política y social experimentada por el estado colombiano, a partir del estado social de derecho, la idea de paz se trastoca, se advierte de forma tridimensional, a saber: como meta, fin y derecho, y en tal sentido ya no es un aspecto circunscrito a la dejación de armas, también es un elemento sobre el cual se sustentas las bases jurídicas e institucionales del estado colombiano.

Con el estado social de derecho surgen una serie de aspectos muy interesantes; en principio porque el estado ya no determina al ser humano como un medio sino como un fin del estado, y entonces la constitución adquiere un carácter personalista, es decir fundada en la persona humana y la satisfacción de sus metas y objetivos como fines de la dirigencia. También ha de considerarse que los pilares del estado social derecho son la salud, educación, empleo y vivienda, de esta forma la garantía de estos coadyuva al consecución de soluciones en temas estructurales e importantes para la vida del individuo.

Habida cuenta de lo mencionado el estado social de derecho propone resolver aspectos cruciales en la vida del ser humano, de tal forma que a través de su materialización el ciudadano puede ver satisfecha su condición básica y esencial. Así las cosas el espectro de paz se ampliará y no solo se basará en la ausencia de conflictos, sino que se enfocará en temas estructurales. Este tipo se denomina paz positiva y se resalta como un prurito de los estados, ya que su eficacia garantiza la existencia de sociedades más justas y además menos propensas a conflictos.

Tomando en cuenta lo mencionado, el presente artículo pretende hacer una explicación sobre las ventajas de esta última tipología. Por ende se segmenta de la siguiente forma: en La primera parte se alude a la paz negativa como mecanismo común utilizado para la resolución de conflictos en Colombia, lo que a la postre no ha generado resultados proficuos, no en vano su consideración como sociedad desigual. En la segunda parte se hace referencia al estado social de derecho y sus características principales, a la luz 
de la constitución política de 1991, y en este sentido determinar su connivencia con la idea de paz positiva, tipo y propósito que se busca alcanzar en Colombia, si se quiere la consolidación de una sociedad justa, equitativa y sin conflictos sociales.

\section{El indulto y la amnistía, elementos de solución de conflictos en Colombia y su relación con la paz negativa.}

Como ya se mencionó en la parte introductoria los armisticios como fórmula de solución de conflictos fueron constantes en Colombia, de esta manera se zanjaban todo tipo de acontecimientos bélicos en esta nación. Para Bernal (2010) "durante el siglo XIX se concedieron 17 amnistías generales, mientras que en el siglo XX se otorgaron nueve" en consecuencia es menester considerar que las diferentes dirigencias optaron por vías raudas, simplemente, para resolver conflictos de manera inmediata. Podríamos determinarlos como acciones paliativas que no lograban la resolución profunda de problemas estructurales.

Conviene determinar que en lo anterior tiene mucha relación la misma cosmovisión que del derecho se había urdido en Colombia, no hay que olvidar que la herencia romanogermánica, de cuya base se había formado el sistema jurídico colombiano, estableció a la ley como la principal fuente del derecho, y en tal circunstancia la regla normativa se entendía como la herramienta totalizante en cuestiones de solución de los problemas acaecidos, sean de la índole que fueren.

La utilización de los instrumentos jurídicos, aunque facilitó las salidas rápidas de las convulsiones internas, no podían dar resultados perdurables, pues se trataba de medios eminentemente de derecho de los cuales se omitían aspectos tan importantes como el dialogo y la existencia de otros aspectos como los intereses de las partes, lo cual 
generaba un retorno cíclico que impedía la consolidación de la institucionalidad y de la paz, distinta a la simple ausencia de conflictos.

De conformidad con lo anterior es preciso establecer que las soluciones establecidas por el derecho al estar basadas en la regla emanada del legislador tienen características muy específicas, como la exterioridad, bilateralidad, heteronomía y coercibilidad, esta última, según la tradición positivista, puntualizada como el elemento garante del orden. Lo mencionado puede carecer de sustancia si se mira de forma excluyente, ya que el imponer o no la sanción sería el único y primordial enfoque en función de la determinación resolutiva. (Bobbio, 2014)

No obstante no se puede descartar ni soslayar que el derecho como toda ciencia obedece a una necesidad social, y por ende, en función de lo anotado, bastaría simplemente con advertir los problemas surgidos entre individuos de una misma sociedad en la que las reglas jurídicas han sido determinantes para lograr una resolución que impida el uso de medios virulentos empleados por los particulares, es decir que el derecho además de evitar las retaliaciones personales, permite la civilidad e impide el retorno a sociedades primitivas en donde imperaba la fuerza como elemento de solución de conflictos.

Convenientemente se ha dicho que el derecho es el subrogado de la guerra Carnelutti (2017) cuyo advenimiento consiste en la solución pacifica de conflagraciones. Lógicamente el belicismo del que se alude no es el común que involucra a todas las sociedades, sino a la guerra que surge entre dos individuos, es decir una micro-guerra, que eclosiona a partir de la inserción de una demanda y una defensa a las pretensiones expuestas.

Se acepta entonces que el derecho ontológicamente se identifica con las disputas y las resuelve con la intermediación de un juez cuya decisión estará signada por la aplicación de normas generales, impersonales y abstractas emanadas de la figura legislativa. Conviene aclarar que, como ya se mencionó, la solución será normativa, indiferente a 
las realidades intrínsecas de los seres humanos, no tendrá, en razón de lo mencionado, fijación en aspectos psicológicos, sentimentales y en veces axiológicos, por ende no habrá integralidad en el fallo definitivo, por tal motivo el derecho, desde su concepción normativista, como lo explica Bobbio (2014), no resuelve el conflicto en su totalidad, si respecto al caso, pero no conforme al individuo.

No es inane referirse a sentimientos en este campo, no es un aspecto irrelevante, es quizás de los elementos el más determinante, toda vez que sin que exista una verdadera reconciliación de la víctima y haya consecución de intangibles, entendidos estos como valores universales en búsqueda del bienestar (Gorjón, 2017) difícilmente habrá existencia de sociedades pacíficas. Como corolario de lo establecido aparecen en la escena social los métodos alternos de solución de conflictos (MASDC), ciencia disruptiva, pues modifica la cosmovisión implantada desde el legalismo, cuya idea se centraba en la creencia del derecho como solución a todos los problemas.

Las diferencias antes señaladas permiten comprender, aún más, que las estrategias asumidas desde la dirigencia nacional, lejos de lograr verdaderos acuerdos, lo que pretendían era solo resolver asuntos inmediatos, sofocar cualquier intento de agresión bajo la consigna de evitar conflagraciones. De lo mencionado podemos determinar dos consideraciones: i) la idea primordial de los diferentes gobiernos a través de la historia era la de lograr ausencia de conflictos a partir de indultos o amnistías, que a su vez, permitieran refundar los caminos entre los partícipes de las contiendas bélicas, (Bernal, 2010) lo plantea de la siguiente forma: " la concesión de amnistías, y posteriormente de indultos, se convirtió en un mecanismo del sistema político por medio del cual se generaba una especie de recomienzo, en el sentido inaugural del pacto social y político" , según esta visión se hacía como si la guerra no hubiese existido, por ende los actores quedaban con resquemores que ulteriormente se zanjaban por medio de muertes 0 violencia. II) esta estrategia utilizada es connivente con la idea de paz negativa, la cual 
según (Jimenez \& Jimenez)2014, siguiendo los planteamientos teóricos de Galtung (1993) es la idea primigenia de la paz, y se caracteriza por "la falta de conflictos armados, de violencia expresa" por tal razón es un corolario manifestar que en Colombia durante muchos años imperó la paz negativa, como la única opción.

De una manera casi que insistente, en el desarrollo del presente artículo, se ha manifestado que esta percepción que se tiene acerca de la paz, no intenta resolver problemas estructurales de la sociedad, y en esa dirección es casi imposible, pretender lograr el advenimiento de contextos que encuentren satisfechos su mínimo vital. De allí se desprende inferencialmente que la consuetudinaria concentración de esfuerzos por lograr una paz basada simplemente en la erradicación de conflictos ha hecho que en Colombia no se resuelvan los problemas más importantes como la inequidad, desigualdad, pobreza y carencia de oportunidades, no en vano según algunos estudios es una de las naciones donde los índices entre riqueza y pobreza alcanzan una brecha ingente. "En el país, $10 \%$ de los más ricos ganan cuatro veces más que $40 \%$ de los más pobres" (Monterrosa, 2017)

Conviene establecer que la pobreza y desigualdad han sido dos males endémicos en el país, y que la solución no es inmediata sino progresiva, empero también se precisan de políticas públicas destinadas a la satisfacción de necesidades primordiales en el ser humano. Lamentablemente la nación se encuentra sumida en una situación donde los intereses del poder predominan ante los problemas que adolecen gran parte de la población. Si a esto le sumamos la idea enquistada e histórica de alcanzar la paz por medios diferentes a aquellos encaminados a la solución de problemas serios, se hallará el caldo de cultivo perfecto para una sociedad débil institucional, política y jurídicamente.

De lo anterior se puede tomar en cuenta dos aspectos: I) la concepción de paz, en este caso negativa, que se ha tenido a lo largo de la historia colombiana no ha permitido avanzar en temas sociales, de primer orden nacional, y solo se basa en la conservación 
de la seguridad. Esencialmente, esto ocurre por la historia violenta que ha arrostrado la nación durante décadas. $Y$ es que son casi que imperceptibles los periodos de tranquilidad experimentados por las personas en este territorio. En un país donde los carteles del narcotráfico, las guerrillas, organizaciones paramilitares, bandas delincuenciales y, tristemente, sectores de las fuerzas castrenses también incurren en transgresiones al orden público, el tema de la seguridad siempre desempeñará un papel transcendente en el colectivo. II) la cognición de la paz; la aulas académicas se encargan de realizar estudios históricos sobre los conflictos y no establecen directrices concerniente a análisis de paz, lo cual supone una idea débil sobre el particular. Pareciere un aspecto inane en ciertos sentidos, sin embargo la construcción de este propósito debe hacerse en todos los frentes.

Con la aparición de los estudios sobre la violencia y la paz, se facilita la comprensión de estas dos importantes cuestiones, y además contribuye al conocimiento y posteriores estrategias de resolución en contextos sometidos a conflictos durante lustros, como el caso colombiano. Según la tipología de la violencia, dimanada de la polemología, la surgida en Colombia obedece a la denomina estructural o institucional, cuya principal causas de surgimiento son los factores de pobreza, desigualdad, desnutrición (Oviedo, 2013) por tal razón se necesita una idea de paz que trascienda el armisticio, y que busque la superación de las causas ya mencionadas.

También es importante considerar que con la aparición de los estudios sobre la violencia y la paz, se facilita la comprensión de estas dos importantes cuestiones, y además contribuye al conocimiento y posteriores estrategias de resolución en contextos sometidos a conflictos durante lustros, como el caso colombiano. Según la tipología de la violencia, dimanada de la polemología, la surgida en Colombia obedece a la denominada estructural o institucional, cuya principal causa de surgimiento son los factores de pobreza, desigualdad, desnutrición (Oviedo, 2013) por tal razón se necesita una idea de paz que trascienda el armisticio, esto es, indultos o amnistías, y que busque la superación de las causas ya mencionadas. 
No es en vano recurrir a la historia para explicar algunos acontecimientos que buscaron solucionarse a partir de indultos, y que posteriormente reaparecieron, esta vez con más vigor y talante cruento. Para citar algunos ejemplos; "la guerra de los mil días" situación bélica suscitada de 1898 a 1902, considerada por Villamizar (2017) como "la prolongación de los enfrentamientos de elites bipartidistas padecidos hacía un siglo" esta confrontación dio apertura al siglo XX y tuvo una causa común, las diferencias entre los partidos tradicionales. La reclamación de uno de ellos, en este caso el liberal, por la nula participación en política que desde 1886 se les establecía fue un factor decisivo para el inicio de las conflagraciones. Para la culminación de este conflicto se empleó la estrategia del indulto, muchos de los participantes, resultaron integrados a la política nacional. Sin embargo, como ya se ha mencionado, el no resolver los factores de fondo, ocasionó que este hecho se suscitará más adelante, y en ese sentido se alude a la que para muchos historiadores fue denominada la época de la Violencia (Aristizábal, 2007), episodio que nuevamente enfrentó a liberales y conservadores, pero esta vez con un recrudecimiento de tal magnitud, y de cuyas repercusiones parecieren indelebles. Cabe determinar que a partir del mismo eclosionan las guerrillas actuales.

Es necesario entonces determinar que la estrategia de indultos y amnistías como forma de resolución de conflictos tiene una relación directa con la paz negativa, puesto que el objetivo trazado por las elites estuvo encaminado a la evitación de conflictos, sin embargo esta, nunca pudo solucionar problemas estructurales y por ende el surgimiento de conflagraciones entre los bandos siempre fue recurrente.

\section{La eficacia del estado social de derecho y su incidencia en la realización de la paz positiva}

La constitución política de Colombia, tras su advenimiento, estableció de manera formal una serie de cambios dirigidos a la satisfacción plena de los derechos inherentes del 
ser humano. Por ende es válido determinar que el estado dirigencial tiene una importante misión en favor de lograr la garantía de derechos del individuo.

Habida cuenta de lo anterior es preciso considerar que la carta política de 1991 tiene un fundamento personalista (Madrid -Malo, 2004) es decir que funda su base doctrinal, política, ideológica y normativa en función del ser humano, y en lograr de este la superación de todos sus objetivos.

Estas importantes prerrogativas trazadas desde el texto constitucional pueden emerger en la realidad gracias a la concepción de estado social derecho que empieza a gestarse epistemológica y teleológicamente con el surgimiento de la norma fundamental de 1991, lo cual permite inferir que los motivos esenciales del constituyente originario fue la de generar una transformación estructural en el estado.

Pese a esto lograr dichos cambios ha resultado tan complicado que en veces puede considerarse como un telos imposible, o una simple utopía planteada por el constituyente, pero que carece de realidad existencial. Pueden enunciarse dos razones para lo anterior; 1) la poca importancia, o mejor, el desinterés mostrado por los dirigentes para materializar lo que está consagrado, es decir para hacer que la constitución sea una simple carta nominal (Naranjo, 2010) donde la realidad no sea efectiva. Esta incompatibilidad entre lo escrito y lo vivencial hacen que no haya materialización de los principales elementos y propósitos establecidos en la norma fundamental y 2) el sistema económico y político impuesto. Las bases liberales con las que se erigió el estado colombiano también pueden ser consideradas como un óbice para el progreso, la razón estriba en la misma situación de competencia que esgrime como principio característico.

Este último aspecto merece ser explicado de forma más pormenorizada. Antes de la constitución de 1991 Colombia experimento la existencia de 15 constituciones nacionales (Valencia, 1997) todas ellas basadas en los intereses de dirigentes y partidos tradicionales, lo que significaba el ascenso de nuevas guerras, en detrimento 
de velar por el cumplimiento organizacional que por razón se le asigna. La de 1886, es decir la antecesora de la actual, se caracterizó por su espíritu conservador, pero mantenía una idea liberal, en sentido económico. Dadas las raíces francesas, inglesas y estadounidenses con las que se erigió el sistema político colombiano, el estado de derecho fue la concepción predominante, donde la ley y el respeto por las libertades individuales son determinantes en su materialización.

El sistema liberal siempre recibió críticas por su excesivo legalismo, amén, de individualismo, que incentivaba la competencia, uno de sus elementos predilectos. En este tipo de sistema se presentan conflictos muy diferentes a los que proponían autores como Marx, por ende se puede establecer que existen connotaciones muy peculiares, en el caso colombiano.

La existencia o no de conflicto en Colombia ha sido uno de los temas más polémicos de los últimos tiempos en este país, y lo es, aunque pareciere un Perogrullo determinar su realidad, en ocasión al significado que este reviste para algunos actores políticos, por ejemplo; desde la mirada "derechista" liderada por el ex presidente Álvaro Uribe Vélez, nunca existió tal acontecimiento, ya que al reconocer su acaecimiento, de forma conexa le otorgaba estatus político a las guerrillas, advirtiéndolas como grupos insurgentes cuya lucha era casi cohonestada por causas objetivas tales como: desigualdad, pobreza, inequidad, entre otros. (Aristizábal, 2007).

La anterior visión de la situación colombiana era partidaria de la denominación guerra, pues así las cosas, debía entenderse que el estado mantenía una lucha contra grupos ilegales que empleaban el terrorismo como elemento de intimidación. Desde esta perspectiva comprender los sucesos en Colombia correspondería a identificar una confrontación bélica entre "buenos" y "malos". De lo cual, tradicionalmente, no podía surgir nada positivo, al contrario solo muertes, peligro, desolación y desasosiego.

Sin embargo, pese a que las confrontaciones bélicas expresan el aspecto más funesto y execrable del ser humano, puede de ella extraerse algunas consideraciones no tan 
negativas. Algunos ven en ella la oportunidad de cambio o trasformación que una sociedad requiere, por supuesto con todo lo peyorativo que eso implica. Tal vez es un momento coyuntural para replantear o incluso de construir estructuras que por el momento parecieren incólumes.

En tal circunstancia la guerra puede ser considerada como elemento de grandes cambios (Silva, 2008), no necesaria, y obviamente, en lo posible evitable, no obstante, al suscitarse podría ocasionar en los actores y agentes externos, modificación en comportamientos y modos de concebir a la sociedad, no inexorablemente malo, al contrario, fundada en el respeto y la tolerancia, puesto que con la experiencia se busca no incurrir en errores anteriores.

El caso colombiano es el ejemplo de lo mencionado anteriormente. Desde los inicios de los diálogos entre el gobierno y la guerrilla de las FARC, una de las principales preguntas surgidas fue: ¿desde cuándo y por qué empezó el conflicto colombiano? Pues existen diversas causas; algunas atribuidas a la negligencia estatal, otras a la lucha del territorio por parte de algunos sectores campesinos, otras adjudican el hecho a un aspecto simplemente de delincuencia común trasladada en forma de guerrilla a las zonas rurales y urbanas, algunos aseveran que es consecuencia de toda una historia de violencia que empieza con la independencia.

Habida cuenta de lo mencionado, resultaría incompleta y hasta absurdo soslayar al marxismo de toda discusión referente a la confrontación bélica colombiana, debido a que el influjo de este pensamiento ha sido, sin ningún tipo de dudas, taxativo en la formación de grupos contestatarios e insurgentes. Por tal razón; es menester considerar tres aspectos: i) una de las causas del conflicto son los factores subjetivos, es decir consideraciones ideológicas que fueron compenetrándose no solo con las concepciones de muchos sectores, entre ellos; obreros, estudiantes, campesinos, sino también con la experiencia de desigualdad, pauperización y olvido en la que se encontraban muchos países latinoamericanos. II) el marxismo representó para muchos, 
un cambio de modelo económico, político y social, toda vez que los sistemas neoliberales no habían arrojado los resultados sociales esperados, por ende la insatisfacción devino en violencia como manera de contrarrestar las vicisitudes acaecidas. III) Debe señalarse a Karl Marx como un avezado sociólogo de su época, su valía intelectiva no es reducible solo a la idea económica, como algunos pretenden mostrarlo, sino que muestra el conflicto, en este caso la lucha de clases antagónicas, como un factor de cambio y progreso; "el motor de la historia" como el mismo decía.

En tal sentido cabe destacar algunos matices que bien pueden resultar paradójicos, en principio porque Marx nunca contempló su idea revolucionaria en contextos no industrializados, donde, a la sazón, terminó imponiéndose a través de sistemas políticos y económicos. También es conveniente dilucidar el componente de lucha de clases. Tal como lo plantea el marxismo, en la dialéctica histórica, en todas las etapas humanas han existido clases sociales opuestas en intereses, desde el esclavismo hasta la erección de la sociedad capitalista. Esta, precisamente, es una de las bases del marxismo, considerar que las oposiciones, en varios sentidos, principalmente el económico, traen consigo luchas y con ellas un paso hacia otras etapas; es decir los conflictos surgen entre sectores disimiles y siempre buscan generar cambios o avances. Sin embargo en las democracias liberales, estas luchas no se originaron entre sectores divergentes, sino entre una misma clase. El ejemplo palmario de lo expuesto es Colombia, un país donde surge una guerrilla de ideología liberal, en sentido tal vez político, pero que con el transcurrir del tiempo se transforma en marxista.

No es aceptable, bajo ninguna circunstancia, creer que existe oposición de clases solo porque la confrontación se presentaba contra el estado, a través de sus fuerzas castrenses, de hecho puede resultar que los intereses sean opuestos y hagan parte de un mismo núcleo social. Por ejemplo si se asume que el militante guerrillero es un campesino de escasa condición económica y a su vez, que el soldado del ejército, con el cual lucha a muerte, es un joven perteneciente a sectores empobrecidos del estado, 
no es encontramos ante un acontecimiento, no solo dantesco y en las antípodas conceptuales del marxismo, sino de luchas entre una misma clase social.

En consecuencia los conflictos, sus características y cualidades, dependen en grado sumo, de los contextos en donde se presenten, en tal sentido los conflictos acaecidos en contextos de predominio liberal, como el colombiano, se suscitan entre una misma clase social. No habrá que soslayar a los principios ontológicos del sistema; competencia y libertad, si se quiere determinar sus causas.

Analizadas las características y peculiaridades de los conflictos en contextos liberales, es menester tomar en cuenta lo acaecido en el estado social de derecho. Bien se sabe que a diferencia del liberalismo el estado social de derecho propugna por el favorecimiento del interés general (Peces-Barba, 2008) y además por el fortalecimiento de los servicios básicos del ciudadano, en lo que respecta a la salud, educación, empleo y vivienda. La materialización del mimo garantiza condiciones dignas de sobrevivencia.

El compromiso de la dirigencia respecto a lo anterior es determinante para lograr la consecución de fines esenciales en lo que respecta a los derechos del ser humano. A su vez existe una relación entre la concreción de un estado social de derecho y la efectividad de la paz positiva, si se tiene en cuenta que esta pretende la superación de problemas estructurales.

En Colombia la violencia ha sido generada por factores de tipo objetivo, como anteriormente se reseñó; desigualdad, pobreza e inequidad, entre otros. La respuesta de la dirigencia hasta este momento histórico ha resultado ineficaz, no han existido políticas públicas encaminadas a solventar estas irregularidades, por tal razón la violencia ha sido prolongada y casi que interminable.

Una de las propuestas que desde este artículo se proponen es la utilización de los métodos alternos de solución de conflictos (MASC) ya que permite ir a fondo con los problemas experimentados por la sociedad, está claro que la simple dejación de armas 
no fue transcendente, no se encontraron razones que permitieran la superación de los conflictos y simplemente retornaron co más fuerza.

Para Lunelli y Meraz (2014) los MASC adquieren una importancia superlativa pues rompe con los paradigmas hasta el momento impuestos en la sociedad, acentuada por las normas adjetivas y por la idea de un derecho fundado en lo represivo, desde este punto de vista, se logra avanzar hacia una sociedad en la que sus miembros no advierten los conflictos como aquellos en donde los resultados o la culminación de los procesos dejan a un vencedor y un perdedor, lo cual genera siempre insatisfacción e inconformidad.

Por ende se precisa establecer que la aplicación de los MASC son idóneos para la materialización del estado social de derecho y consecuentemente con la concreción de la paz positiva, única opción posible de lograr un contexto que garantice sosiego social y cumplimiento del bienestar general.

\section{Conclusiones}

La violencia en Colombia se ha prolongado durante muchas décadas en razón de la aplicación de medidas como los indultos y amnistías, lo cual puede ser importante si se quiere resolver el problema conflictivo de forma momentánea, sin embargo el devenir histórico ha demostrado que las repercusiones no dejan de ser funestas, debido a que estos retornan con mayor vigor, el caso de la denominada "guerra de los mil días" y su conexión con la etapa llamada la "violencia" es un ejemplo claro de lo mencionado.

En sentido a lo que se ha mencionado el concepto de paz negativa ha imperado en Colombia en toda su historia, lo anterior ha sido un óbice del progreso social, ya que esta no resuelve los problemas de fondo como pobreza, inequidad y desigualdad, 
latentes todavía en este contexto, no en vano la consideración de ser una de las sociedades donde la brecha entre ricos y pobres cada vez más se agiganta.

El surgimiento de la constitución de 1991 y la refundación en cuanto a la modalidad de estado, es decir, ya no derecho de corte individualista, sino social y de derecho donde prevalezca el interés general y la satisfacción de derechos sociales como; la salud, educación y el empleo.

Se ha determinado que la materialización del mismo es considerablemente importante si se pretende lograr una paz positiva, esta entendida como la posibilidad de superar problemas estructurales.

La diferencia estriba en que la paz negativa resuelve la violencia directa, aquella que es causada por homicidios, hurtos, secuestros, y la positiva es más enfática al momento de solucionar temas que aquejan a la sociedad en su sentido más crítico. Se debe propender por el empleo de los MASC como herramientas que conlleven a la superación de la violencia distinta a los utilizados históricamente. Los métodos alternos de solución de conflictos, son congruentes con la paz positiva y así mismo con el estado social de derecho. De allí su importancia y consideración superlativa para el progreso social. 


\section{Referencias.}

Aristzábal, G. (2007). Metamorfosis. Globalización y violencia . Bogotá: Desde abajo.

Bernal, C. (2010). Excepcionalidad permanente: un ensayo de comprensión histórica de la justicia penal de excepcipon y la justicia transicional en Colombia . En Transiciones en contienda. Dilemas de la justicia transicional en Colombia y en la experiencia comparada (págs. 114-155). Bogotá: Centro internacional para la justicia transicional .

Bobbio, N. (2014). Teoría General Del Derecho . Bogotá: Temis.

Carnellutti, F. (2017). Cómo se hace un proceso . Bogotá: Temis .

Gorjón, F. (2017). Mediación, su valor intangible y efectos operativos. Ciudad de Mexico : tirant lo blanch. Ciudad de México : Tirant Lo Blanch.

Jimenez, F., \& Jimenez, F. (2104). Una Historia De La Investigación Para La Paz. Historia de la paz online .

López, M. (2011). Teorías Para La Paz Y Perspectivas Ambientales Del Desarrollo Como Diálogos De Imperfectos. Luna azul, 85-96.

Lunelli, C., \& Meraz, A. (2014). Jurisdicción y medios alternativos de resolución de conflictos: una opción para las cuestiones ambientales. Opción Jurídica . encontrado en : http://www.scielo.org.co/pdf/ojum/v13n26/v13n26a02.pdf

Madrid- Malo, M. (2004). Derechos fundamentales. conózcalos, ejérzalos y defiéndalos . Bogotá: 3R editores .

Monterrosa, H. (2017). Según el banco mundial, Colombia es e segundol país más deisgual de América latina. El país. encontrado en: https://www.larepublica.co/economia/segun-el-banco-mundial-colombia-es-el-segundopais-mas-desigual-de-america-latina-2570469

Naranjo, V. (2010). Teoría Constitucional e instituciones políticas . Bogotá: Temis .

Oviedo, D. (2013). Eco(bio)lencia, irenología y lucha por la paz en nuestro mundo unico . Iztapalapa Revista de Ciencias Sociales y Humanidades , 41-82.

Peces-Barba, G. (2008). El estado social de derecho . Revista de historiografia (rev histo) , 91-96. 
Silva, G. (2008). La teoría del conflicto. Un marco teorico necesario . Prolegomenos, 29-43.

Valencia, H. (1997). Cartas de Batalla. Una crítica del constitucionalismo Colombiano . Bogotá : Universidad nacional y Cerec .

Villamizar, D. (2017). Las guerrillas en Colombia. Una historia desde los origenes hasta los confines. Bogotá : Debate . 